\title{
Spectroscopic analysis of a-C and a-CNx films prepared by ultrafast high repetition rate pulsed laser deposition
}

McCann, R., Roy, SS., Papakonstantinou, P., McLaughlin, JAD., \& Ray, SC. (2005). Spectroscopic analysis of a-C and a-CNx films prepared by ultrafast high repetition rate pulsed laser deposition. Journal of Applied Physics, 97(7), 73522-1. https://doi.org/10.1063/1.874300

Link to publication record in Ulster University Research Portal

\section{Published in:}

Journal of Applied Physics

Publication Status:

Published (in print/issue): 01/04/2005

DOI:

$10.1063 / 1.874300$

\section{Document Version}

Publisher's PDF, also known as Version of record

\section{General rights}

Copyright for the publications made accessible via Ulster University's Research Portal is retained by the author(s) and / or other copyright owners and it is a condition of accessing these publications that users recognise and abide by the legal requirements associated with these rights.

\section{Take down policy}

The Research Portal is Ulster University's institutional repository that provides access to Ulster's research outputs. Every effort has been made to ensure that content in the Research Portal does not infringe any person's rights, or applicable UK laws. If you discover content in the Research Portal that you believe breaches copyright or violates any law, please contact pure-support@ulster.ac.uk. 


\title{
Spectroscopic analysis of $\mathrm{a}-\mathrm{C}$ and $\mathrm{a}-\mathrm{CN}_{x}$ films prepared by ultrafast high repetition rate pulsed laser deposition
}

\author{
R. McCann, S. S. Roy, ${ }^{\text {a) }}$ P. Papakonstantinou, and J. A. McLaughlin \\ Nanotechnology Research Institute (NRI), School of Electrical and Mechanical Engineering, \\ University of Ulster at Jordanstown, Newtownabbey, County Antrim BT37 OQB, Northern Ireland \\ S. C. Ray \\ Instituto de Ciencia de Materiales de Madrid, Consejo Superior de Investigaciones Cientificas, \\ Campus de Cantoblanco, E-28049 Madrid, Spain
}

(Received 7 June 2004; accepted 19 January 2005; published online 28 March 2005)

\begin{abstract}
The effect of nitrogen partial pressure on amorphous carbon nitride $\left(a-\mathrm{CN}_{x}\right)(0.0 \leqslant x \leqslant 0.17)$ and laser fluence on amorphous carbon $(a-\mathrm{C})$ films prepared by ultrafast high repetition rate pulsed laser deposition has been studied. The chemical bonding structure of the films was investigated by $\mathrm{x}$-ray photoelectron spectroscopy (XPS), Raman spectroscopy, and Fourier transform infrared (FTIR) analysis. XPS studies of films revealed an increase in the $\mathrm{CN}$ sites at the expense of CC bonded carbon sites as nitrogen content in the films increased. Films $(a-C)$ prepared as a function of laser fluence showed an increase in $s p^{3}$-bonded carbon as laser fluence was increased from 0.36 to $1.7 \mathrm{~J} / \mathrm{cm}^{2}$. The $I_{D} / I_{G}$ ratio and $G$ peak position increased as a function of nitrogen whereas the full width at half maximum (FWHM) of the $G$ peak decreased. This is indicative of either an increase in the size or number of the $s p^{2}$ sites. Films prepared as a function of laser fluence revealed a decrease of the $I_{D} / I_{G}$ ratio and an increase in the FWHM of the $G$ peak. The use of two visible excitation wavelengths when analyzing the samples indicated a resonant process. FTIR analysis revealed an increase in the peaks attributed to $\mathrm{C}=\mathrm{N}$ bonds as well as indicated a tiny amount of $\mathrm{C} \equiv \mathrm{N}$ bonds within the nitrogen-doped films. Additionally, surface morphology analysis showed a greater particle density on films prepared at the highest laser energy in comparison to those prepared at lower fluences. Film hardness characterized by nanoindentation revealed that films became softer as a function of nitrogen content. (C) 2005 American Institute of Physics. [DOI: 10.1063/1.1874300]
\end{abstract}

\section{INTRODUCTION}

Diamondlike carbon (DLC) is a form of $a$-C that has been intensively studied over the years. ${ }^{1}$ In general it consists of a mixture of $s p^{3}$ and $s p^{2}$ bonds in an amorphous network. The technological interest in this material stems from their exceptional properties such as chemical inertness, mechanical hardness, low friction coefficient, and ease of fabrication. One of the desirable features of $a$-C films is that they can be easily doped with other elements such as boron, fluorine, nitrogen, silicon, and various metals to modify their properties. Doping with nitrogen, in particular, has attracted a lot of interest in the research community ever since the theoretical predictions of $\beta-C_{3} N_{4}$ carbon nitride phase by Liu and Cohen. ${ }^{2}$

Synthesis of $a-\mathrm{C}$ and $\mathrm{CN}_{x}$ films through various techniques such as ion beam and ion-beam-assisted deposition, ${ }^{3-5}$ pulsed laser deposition, ${ }^{6,7}$ chemical-vapor deposition, ${ }^{8,9}$ and sputtering ${ }^{10-13}$ has been reported. Doping $a$-C films with nitrogen has the added advantage in that it has also been shown to reduce stress in films. ${ }^{14}$ These characteristics make this material attractive as it lends itself to numerous applications in optical and tribological coatings. ${ }^{15}$

So far most of the work on film synthesis has concentrated on the use of excimer laser or solid-state lasers whose

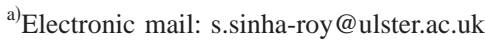

pulse duration is in the nanosecond range. ${ }^{16,17}$ The conventional nanosecond pulsed lasers result in thermal loading of the ablation target, causing particulates to form, and in optical pumping of the ablation plasma, initiating an increase in the mean thermal energy of the plasma. Processing with femtosecond laser pulses offers unique characteristics of minimal thermal damage and well-defined ablation thresholds. These attributes have been utilized in the micromachining (microetching or microdeposition) of fine structures. ${ }^{18}$

Large area deposition of tetrahedral carbon by femtosecond lasers is largely unexplored. A variety of characteristics in ultrafast laser ablation plumes could lead to significant improvements in the quality of the deposited films. Nanosecond laser pulses tend to generate explosive phase change, strong shock waves, and formation of particle clusters. On the other hand, ultrashort laser pulses impact weaker mechanical effects since plasmas form after the termination of the laser pulse and do not absorb part of the incident radiation. These characteristics can be applied to synthesize new materials.

Depending on laser intensity and repetition rate of the femtosecond pulses new modes of vapor-substrate interaction can appear, which strongly influence the chemical, structural, and morphological properties of the films. Previous experiments ${ }^{17}$ focused in the high laser intensity regime (3 $\times 10^{14}$ to $6 \times 10^{15} \mathrm{~W} / \mathrm{cm}^{2}$ ), indicating a decrease in the $s p^{3}$ content with increasing laser intensity. 
Use of high repetition rate $(10 \mathrm{KHz}$ to $\mathrm{MHz})$ in conjunction with low pulse energy $\mu \mathrm{J}$, short (picosecond) laser pulses, and large target substrate distances $(15 \mathrm{~cm})$ has demonstrated to lead to particle-free amorphous carbon films. ${ }^{19}$ Due to the low energy of the pulse the number of atoms evaporated by each pulse is reduced to the point where it becomes impossible for microscopic lumps of the carbon material to be ejected, thus preventing the source of particle contamination from the film. Moreover, to compensate for the low evaporation rate the pulse repetition rate has to be increased to a maximum value.

Recent experiments ${ }^{20}$ employing an average repetition rate $(1 \mathrm{KHz})$ and laser pulses $(1.5 \mathrm{~mJ})$ of femtosecond duration resulted in films with predominant $s p^{3}$ hybridization $(\sim 70 \%)$ and high wear resistance. Synthesis of amorphous carbon nitride films has also been performed using sublasers with low repetition rate. ${ }^{21-23}$ However, those studies were focused mainly to the surface morphology and not to the actual structure of the films. Motivated from this deficiency of studies we have investigated the growth and bonding states of both $a-\mathrm{C}$ and $a-\mathrm{CN}_{x}$ films using a $1-\mathrm{KHz}, 50-\mathrm{fs}$ Ti:sapphire laser.

The combination of x-ray photo-electron-spectroscopy (XPS), Fourier transform infrared (FTIR) analysis, and Raman spectroscopy ${ }^{24-33}$ has proved very successful for analyzing the structure of $a-\mathrm{C}$ and $a-\mathrm{CN}_{x}$ films. These techniques are available in most laboratories and in this paper we have used those for studying the electronic structure of the $a$-C and $a-\mathrm{CN}_{x}$ films prepared by femtosecond laser ablation. However, there exist inconsistencies in specifying the effect of nitrogen on Raman parameters of carbon nitride films due to the different methodologies employed. Here we also present a wavelength-dependent resonant Raman-scattering study and nanoindentation analysis of the films in order to provide a clear idea into the bonding configurations of the films.

\section{EXPERIMENT}

For this work $P$-type silicon wafers were used. The substrates were cleaned with acetone and placed in an ultrasonic bath for 5 min. Following this, they were dipped in hydrofluoric acid (10:1 ratio) for $40 \mathrm{~s}$ to remove the native oxide layer. The samples were then rinsed with water and dried prior to being placed in the chamber for deposition. The pulsed laser deposition (PLD) system consisted of a Tisapphire laser $(\lambda 800 \mathrm{~nm})$ with a repetition rate of $1 \mathrm{KHz}$ and a full width at half maximum (FWHM) of $50 \mathrm{fs}$. The laser beam was focused at an angle of incidence of $45^{\circ}$ to the target normal. The substrate-to-target distance remained at 4 $\mathrm{cm}$. All depositions took place at room temperature (see Table I).

The first series of films were prepared as a function of nitrogen pressure. Prior to each deposition run the chamber was pumped down to approximately $9.8 \times 10^{-6}$ mbar. A laser fluence of $0.64 \mathrm{~J} / \mathrm{cm}^{2}$ was used to ablate a graphite target (purity 99.999\%). During deposition nitrogen was released into the chamber with a mass flow controller used to control the background nitrogen pressure. Films were prepared at
TABLE I. PLD parameters used for the synthesis of $a$-C and $a-\mathrm{CN}_{x}$ films.

\begin{tabular}{ll}
\hline \hline Laser source & Ti:sapphire $(800 \mathrm{~nm})$ \\
\hline Pulse width (FWHM) & $50 \mathrm{fs}$ \\
Repetition rate & $1 \mathrm{KHz}$ \\
Target-to-substrate distance & $4 \mathrm{~cm}$ \\
Substrate & $\mathrm{Si}(P$ type $)$ \\
Deposition temperature & Room temperature \\
Chamber pressure & $9.8 \times 10^{-6} \mathrm{mbar}$ \\
Nitrogen pressure & $1 \times 10^{-3}-0.7 \mathrm{mbar}$ \\
Laser fluence & $0.36-2.12 \mathrm{~J} / \mathrm{cm}^{2}$ \\
Peak intensity & $7.2 \times 10^{12}-4.24 \times 10^{13} \mathrm{~W} / \mathrm{cm}^{2}$ \\
\hline \hline
\end{tabular}

various nitrogen pressures ranging from $1 \times 10^{-3}$ to 0.7 mbar. The deposition time for this series of films was approximately $15 \mathrm{~min}$ in which the thickness ranged from 150 to $200 \mathrm{~nm}$ for samples with low nitrogen content (from 0 to 4.3 at. \% N). At higher nitrogen contents (9-17 at. \% N) film thickness was approximately $95-115 \mathrm{~nm}$. A second series of samples were prepared as a function of laser fluence without the introduction of nitrogen. For this experiment the laser fluence was varied from 0.36 to $2.12 \mathrm{~J} / \mathrm{cm}^{2}$. The deposition time for these films was approximately 7 min giving a lower film thickness (in the range of 50-105 nm).

XPS analysis of the films was carried out with a XSAM 800 (Kratos) spectrometer using a nonmonochromated $\operatorname{Mg} K \propto(1253.6 \mathrm{eV})$ x-ray source and a hemispherical electron energy analyzer in a vacuum of approximately 1.33 $\times 10^{-10}$ mbar. To take into account of charging effects the peaks were calibrated to the standard binding energy of the carbon peak $(285.0 \mathrm{eV})$. The spectra background was then subtracted using the Shirley method. The deconvolution of C $1 s$ and $\mathrm{N} 1 s$ envelopes was performed using Gaussian line shapes. The atomic percentages of the $\mathrm{C} 1 s$ and the $\mathrm{N} 1 s$ were calculated from the total area of the XPS signals corresponding to the $\mathrm{C} 1 s$ and $\mathrm{N} 1 s$ core levels using the sensitivity factors of the instrument. ${ }^{33}$

Raman characterization was performed using an ISA Labram 300 Raman spectroscope. The system was equipped with a BX 40 microscope coupled confocally to a liquidnitrogen-cooled spectrograph. The excitation was carried out with a 20-mW He:Ne laser with a wavelength of $632.8 \mathrm{~nm}$ and a 50-mW Ar-ion laser with a wavelength of $514 \mathrm{~nm}$. All measurements were made by focusing a laser filtered with a $0.1 \%$ transmission filter through a $100 \times$ magnification lens onto the surface of the sample to avoid thermal damage. An appropriate filter for spectral acquisition was selected followed by the spectra being taken over a 20 -s period. For all measurements a confocal hole of $400 \mu \mathrm{m}$, a spectrograph entrance slit of $150 \mu \mathrm{m}$, and a 1800-grooves/mm diffraction grating were employed. FTIR spectra were measured by BIO-RAD-FTS-3000MX spectrophotometer in the transmission mode.

Nanoindentataion measurements of the samples were performed using a nanoindenter XP (Nano Instruments). All measurements were taken in the continuous stiffness mode (CSM), whereby upon being loaded in standard mode a small ac modulation is superimposed on the applied load. This allows the stiffness data from the load displacement 


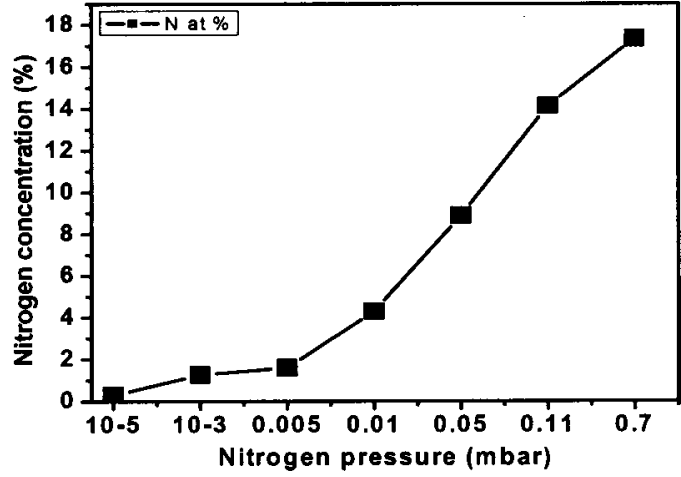

FIG. 1. Nitrogen concentration revealed by XPS as a function of nitrogen pressure.

curves to be acquired continuously throughout the indentation process. Using the Oliver and Pharr model ${ }^{34}$ we can then derive the hardness as well as the modulus of elasticity from the stiffness data. In this experiment a series of nine indents were performed on each sample spaced at approximately $20 \mu \mathrm{m}$ apart with the results averaged. The ac nanoindentations were performed at maximum depths of $50 \mathrm{~nm}$ at a constant strain rate-loading segment of $0.05 \mathrm{~s}^{-1}$ To ensure that the Berkovich tip geometry was stable throughout the tests we measured the hardness of a standard bulk silica sample before and after each experiment. ${ }^{33}$ The nanoindenter continuously measured the load and displacement of the three-sided pyramidal diamond indenter as it pushed into the sample. No noticeable differences were observed suggesting no appreciable tip wear.

\section{RESULTS AND DISCUSSION}

\section{A. X-ray photoelectron spectroscopy}

The XPS technique is frequently used for analyzing the bonding configuration of $a-\mathrm{CN}_{x}$ thin films; however, the interpretation of the data has been subjected to considerable debate ever since research on carbon nitride films started over a decade ago. ${ }^{35}$ Figure 1 shows the nitrogen content within the films as the nitrogen pressure was increased during each deposition run. Figure 2 shows the normalized $\mathrm{C} 1 \mathrm{~s}$ and $\mathrm{N} 1 s$ spectra of our $a-\mathrm{CN}_{x}$ films containing various nitrogen contents. We can see that the $\mathrm{C} 1 s$ peaks become broader and more asymmetric as greater amounts of nitrogen are incorporated into the films. Whereas the $\mathrm{N} 1 s$ spectra reveal a shift towards a higher binding energy at higher nitrogen concentrations.

Usually in the literature the $\mathrm{C} 1 s$ envelopes of $a-\mathrm{CN}_{x}$ films are deconvoluted using several components. To date, the identification of local bonding states in $\mathrm{C} 1 s$ spectra is not definitive. In the literature three alternative assignment methods are commonly employed. Firstly, Ronning et al. ${ }^{35}$ showed that one to five Lorentzian lines had to be used to obtain a proper fit with the C $1 s$ core-level spectra of different samples within the energy range of the peak position 284.5-289.9 eV. The peak centered at the lowest energy was assigned to carbon atoms in a pure $\mathrm{C}$ environment. The next two peaks were close to 285.6 and $286.6 \mathrm{eV}$ which are assigned to $\mathrm{C}-\mathrm{N}$ and $\mathrm{C}=\mathrm{N}$, respectively. It is assumed that the

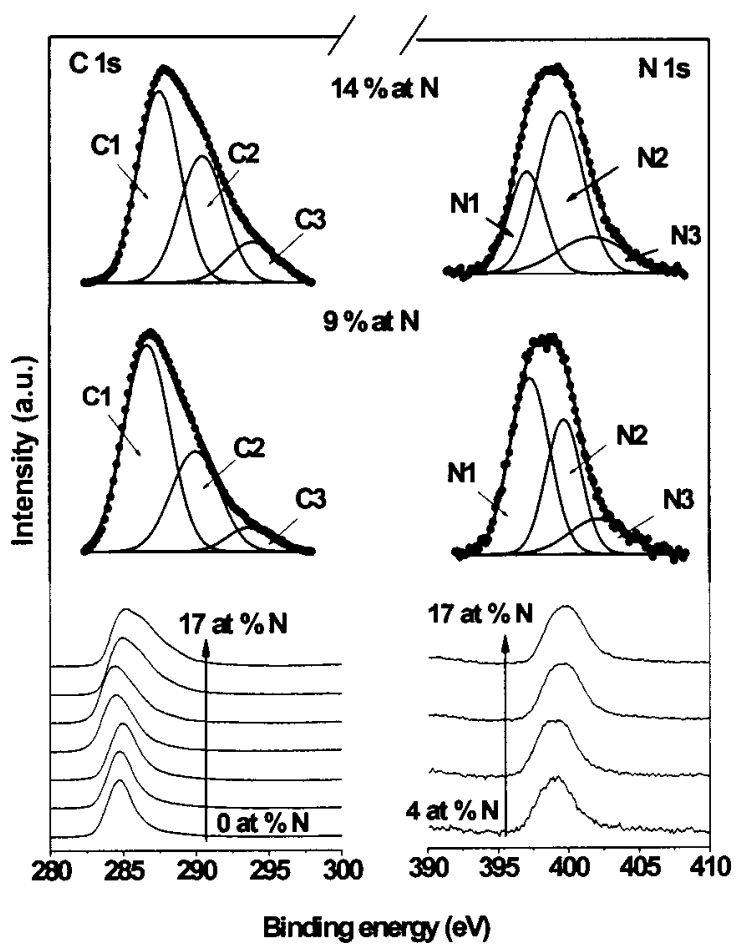

FIG. 2. Deconvolution of the C $1 s$ and $\mathrm{N} 1 s$ spectra of $\mathrm{CN}_{x}$ films at different nitrogen concentrations.

two high-energy peaks at approximately 288 and $290 \mathrm{eV}$ arise from $\mathrm{C} s p^{3}$ in a $\mathrm{C}_{3} \mathrm{~N}_{4}$ environment ${ }^{35}$ and $\mathrm{C}-\mathrm{O}$ species, respectively. Secondly, Das et al. ${ }^{36}$ used three peaks in the $\mathrm{C}$ $1 s$ within the ranges of 284.6, 286.5, and $289 \mathrm{eV}$ and are assigned as carbon bonds (both and $\mathrm{C}=\mathrm{C}$ and $\mathrm{C}-\mathrm{C}$ ), carbon coordinated nitrogen bonds $(\mathrm{C}-\mathrm{N}$ and $\mathrm{C}=\mathrm{N})$. The third peak located at $287.6-287.8 \mathrm{eV}$ is attributed to $\mathrm{C}=\mathrm{O}$ bonds. The third opinion ${ }^{37,38}$ reveals that the peaks situated at 284.5, 285.2, 286.5, and $288.6 \mathrm{eV}$ are attributed to $\mathrm{C}-\mathrm{C}, \mathrm{C}=\mathrm{N}$, $\mathrm{C}-\mathrm{N}$ or $\mathrm{C} \equiv \mathrm{N}$, and $\mathrm{C}-\mathrm{O}$ bonds, respectively. In this paper our C $1 s$ XPS spectra were fitted using three Gaussian lines, respectively. Although fitting the spectra with three peaks is less informative, it is also not confusing. The three peaks in the C $1 s$ arise within the range of 284.2-284.6, 286.0-286.4, and 287.4-287.8 eV. The first two peaks are assigned as carbon bonds (both $\mathrm{C}=\mathrm{C}$ and $\mathrm{C}-\mathrm{C}$ ), carbon coordinated nitrogen bonds $(\mathrm{C}-\mathrm{N}$ and $\mathrm{C}=\mathrm{N})$, respectively. ${ }^{36}$ The third peak located at $287.6-287.8 \mathrm{eV}$ is attributed to $\mathrm{C}=\mathrm{O}$. These peaks have been denoted as $\mathrm{C} 1, \mathrm{C} 2$, and $\mathrm{C} 3$, respectively. Table II shows the bonding percentage area, FWHM, and intensity ratios of the curve fittings for the $\mathrm{C} 1 s$ spectra. We note that as the films become more nitrogenated the relative binding area of peak $\mathrm{C} 1$ (CC) bonds decreases from $68 \%$ at 4 at. $\% \mathrm{~N}$ to $45 \%$ at 17 at. $\% \mathrm{~N}$. At the same time we observed that the area of peak $\mathrm{C} 2(\mathrm{CN})$ increased from $28 \%$ to approximately $39 \%$. It is noted that the FWHM of peak C1 becomes narrower (from 1.91 to $1.77 \mathrm{eV}$ ) as too does peak C2 (from 2.05 to $1.77 \mathrm{eV}$ ). This can be explained due to the increase in the nitrogen incorporation increasing the intensity of the $\mathrm{CN}$ peak at the expense of the CC peak. This is shown by the increase in the $I(\mathrm{CC}) / I(\mathrm{CN})$ ratio (from 0.41 to 0.87 ).

The fitting of the $\mathrm{N} 1 s$ spectra usually entails three peaks in the range of 398.3-398.8 (N1), 399.6-400.3 (N2), and 
TABLE II. The $\mathrm{C} 1 s$ bonding areas and peak widths of $a-\mathrm{CN}_{x}$ films.

\begin{tabular}{|c|c|c|c|c|c|c|c|}
\hline \multirow[b]{2}{*}{$\mathrm{N}$ at. $\%$} & \multirow[b]{2}{*}{ I CN/I CC } & \multicolumn{2}{|c|}{ C1 $284.4+/-0.2 \mathrm{eV}$} & \multicolumn{2}{|c|}{$\mathrm{C} 2286.2+/-0.2 \mathrm{eV}$} & \multicolumn{2}{|c|}{ C3 $287.6+/-0.2 \mathrm{eV}$} \\
\hline & & Area $(\%)$ & FWHM & Area $(\%)$ & FWHM & Area $(\%)$ & FWHM \\
\hline 4 & 0.41 & 68 & 1.91 & 28 & 2.05 & 4 & 1.63 \\
\hline 9 & 0.52 & 62 & 1.86 & 32 & 1.95 & 6 & 1.69 \\
\hline 14 & 0.64 & 55 & 1.71 & 35 & 1.81 & 10 & 1.86 \\
\hline 17 & 0.87 & 45 & 1.77 & 39 & 1.77 & 16 & 2.25 \\
\hline
\end{tabular}

401.3-401.7 (N3) eV. The best fits to $\mathrm{N} 1 s$ envelopes for the $a-\mathrm{CN}_{x}$ films resulted in three Gaussian peaks $(\mathrm{N} 1, \mathrm{~N} 2$, and N3) at binding energies mentioned in Table III. The literature contains contradictory interpretations on the assignment of the first two peaks. Some authors have assigned the peaks $\mathrm{N} 1, \mathrm{~N} 2$, and $\mathrm{N} 3$ to $\mathrm{C}-\mathrm{N}, \mathrm{C}=\mathrm{N}$ and $\mathrm{NO}$, respectively. ${ }^{39}$ Other researchers have suggested that peak N1 is related to the $\mathrm{C}=\mathrm{N}$ bonds and peak $\mathrm{N} 2$ is related to the $\mathrm{C}-\mathrm{N} .{ }^{40} \mathrm{An}-$ other opinion is that both $\mathrm{N} 1$ and $\mathrm{N} 2$ peaks are $s p^{2}$ hybridized and bonded to $s p^{2}$ carbon. ${ }^{41}$ Table III reveals that the area and FWHM of peak N1 show a decreasing trend (from $53 \%$ and 2.21 to $35 \%$ and $1.73 \mathrm{eV}$ ) as greater amounts of nitrogen are incorporated, whereas peak N2 shows the opposite trend (an increase from $41 \%$ and $2 \mathrm{eV}$ to $50 \%$ and 2.27 $\mathrm{eV})$. These results indicate that the films became more graphitelike as greater amounts of nitrogen were added during the deposition of the films and are confirmed by nanoindentation hardness measurements. The ratio N1/N2 decreases with the increase of $\mathrm{N}$ at. \% and a decrease of hardness value (see Sec. III E clearly indicated that N2 is related to $s p^{2}-\mathrm{CN}$. We assign that the peak N3 is related to $\mathrm{NO}$ and the peak $\mathrm{N} 1$ is related to $\mathrm{C}-\mathrm{N}$ and $\mathrm{C} \equiv \mathrm{N}$ (if present).

In addition to carbon and nitrogen, oxygen was also detected in the samples. This superficial contamination can be attributed to the prolonged exposure of the samples to the laboratory atmosphere. Samples prepared at higher nitrogen pressures tended to have a slightly higher concentration of oxygen (see Table II). This can be explained due to the presence of nitrogen and the minor contamination of oxygen within the carbon network, which increases the electronegativity of the $\mathrm{CN}_{x}$ compound. Due to this increase the films tend to become more polar and thereby absorb $\mathrm{H}_{2} \mathrm{O}$ molecules present in the laboratory atmosphere, thus increasing the oxygen content within the films. This is shown by the increased trends observed in peaks $\mathrm{C} 3$ and N3 in Tables II and III.
The C $1 s$ spectra of the amorphous carbon films prepared as a function of laser fluence (with no nitrogen addition) were deconvoluted into two main contributions at 284.4 (C1) and $285.2 \mathrm{eV}(\mathrm{C} 2)$, which are assigned to $s p^{2}$ and $s p^{3}$ bonding. A third peak was also present at $287.6 \mathrm{eV}$ (C3), which was indicative of the presence of $\mathrm{C}=\mathrm{O}$ bonds. Figure 3 displays the deconvolution of the $\mathrm{C} 1$ s peak of $a$-C films prepared at two different laser fluences. We can see the change in peaks $\mathrm{C} 1$ and $\mathrm{C} 2$ as the fluence is increased from 0.36 to $1.7 \mathrm{~J} / \mathrm{cm}^{2}$. An increase in peak $\mathrm{C} 2$ at $1.7 \mathrm{~J} / \mathrm{cm}^{2}$ suggests that the film becomes more diamondlike. This is confirmed in Fig. 4, which shows the $s p^{2}-\mathrm{C}, s p^{3}-\mathrm{C}$, and $\mathrm{C}=\mathrm{O}$ bonds plotted as a function of laser fluence. A clear trend can be observed, as the fluence is increased the $s p^{3}$ bonding within the films increases while at the same time the $s p^{2}$ bonds decrease. However, at the highest fluence $\left(2.12 \mathrm{~J} / \mathrm{cm}^{2}\right)$ the $s p^{2}$ bonding increased slightly at the expense of $s p^{3}$ bonding. In summary it is worth emphasizing the following points from the XPS analysis: First, for amorphous nitrogenated carbon $\mathrm{C} 1 s$ peak fitting revealed the formation of $\mathrm{CN}$ bonds at the expense of $\mathrm{CC}$ bonds as a function of nitrogen pressure. During N $1 s$ peak fitting, we also observed that for higher $\mathrm{N}$ content films the majority of $\mathrm{CN}$ bonds are $\mathrm{N}-s p^{2} \mathrm{C}$. Secondly, for pure carbon films an increase in laser fluence up to $1.7 \mathrm{~J} / \mathrm{cm}^{2}$ was accompanied by a corresponding increase in the $s p^{3}$ bonds. However, at a fluence of $2.12 \mathrm{~J} / \mathrm{cm}^{2}$, we observed a slight increase in $s p^{2}$ content, which suggests that there is an optimum laser fluence for the growth of $s p^{3}$-rich films.

\section{B. Raman spectroscopy}

Raman spectroscopy has proved to be a popular nondestructive technique successfully used in the characterization of structural information of $a-\mathrm{C}$ films. The Raman spectrum of diamond has a single Raman active mode at $1332 \mathrm{~cm}^{-1}$ whereas the Raman spectrum of single-crystal graphite con-

TABLE III. The $\mathrm{N} 1 s$ bonding areas and peak widths of $a-\mathrm{CN}_{x}$ films.

\begin{tabular}{|c|c|c|c|c|c|c|c|}
\hline \multirow[b]{2}{*}{$\mathrm{N}$ at. $\%$} & \multirow[b]{2}{*}{ IN1/IN2 } & \multicolumn{2}{|c|}{ N1 $398.3-398.8 \mathrm{eV}$} & \multicolumn{2}{|c|}{ N2 $399.6-400.3 \mathrm{eV}$} & \multicolumn{2}{|c|}{ N3 $401.3-401.7 \mathrm{eV}$} \\
\hline & & Area $(\%)$ & FWHM & Area $(\%)$ & FWHM & Area $(\%)$ & FWHM \\
\hline 4 & 1.70 & 53 & 2.21 & 41 & 2 & 6 & 2.36 \\
\hline 9 & 1.49 & 50 & 2 & 43 & 1.76 & 7 & 2.92 \\
\hline 14 & 0.49 & 39 & 1.73 & 51 & 2.22 & 10 & 3.37 \\
\hline 17 & 0.46 & 35 & 1.74 & 50 & 2.27 & 15 & 3.57 \\
\hline
\end{tabular}




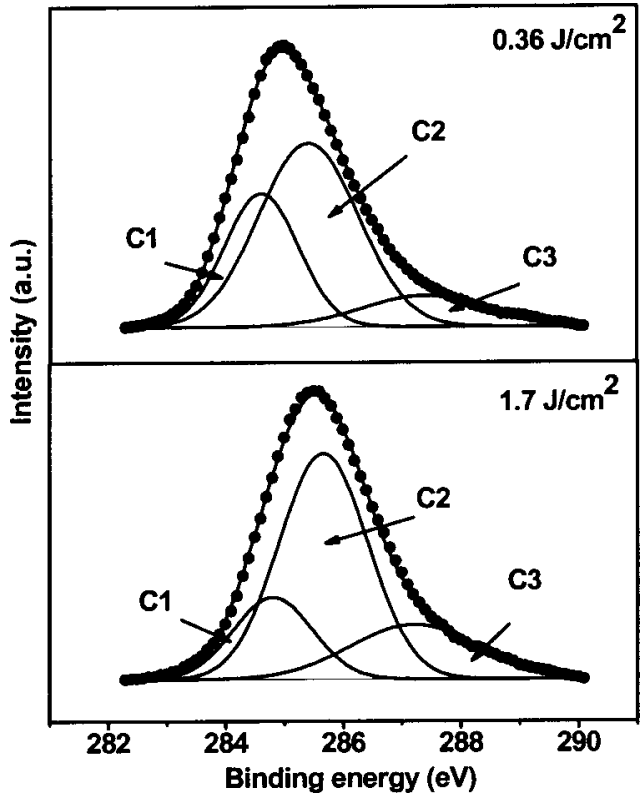

FIG. 3. Deconvolution of the $\mathrm{C} 1 s$ envelopes of $a$-C films at two different laser fluences.

sists of a narrow peak at $1580 \mathrm{~cm}^{-1}$ and is labeled $G$ for graphite. In the case of polycrystalline graphite two narrow bands exist. The previously mentioned $G$ band located at $1580-1600 \mathrm{~cm}^{-1}$ (which is associated with the $E_{2 g}$ mode) and a second $D$ band located at $1350 \mathrm{~cm}^{-1}$ (which is associated with the $A_{1 g}$ mode) only become active in the presence of disorder. Therefore, the Raman spectra of nanocrystalline and amorphous carbon are dominated by $G$ and $D$ peaks of varying intensity, width, and position. The reason for the dominance of $G$ and $D$ bands can be attributed to the scattering of $s p^{2}$ sites within $a$-C. This in itself creates a problem as the $\pi$ states have a lower energy than the $\sigma$ states making them much more polarizable. It has been reported that this gives the $\pi$ states a much larger Raman cross section (approximately 50-230 times larger) than $s p^{3}$ sites. $^{42}$

Usually Raman spectra of carbon nitride films are decomposed using three different approaches, which have generated confusion. In the first ${ }^{33,43-45}$ and arguably the most widely reported approach, both the $D$ and $G$ peaks are fitted with two Gaussian distribution functions and a linear background. The second ${ }^{46,47}$ one is based on a Breit-WignerFano (BWF) and a Lorentzian shape fitting for the $G$ and $D$

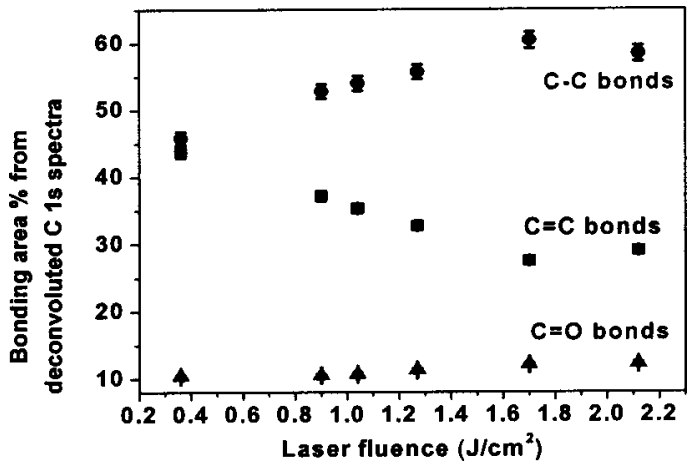

FIG. 4. Curve fitting results of the $\mathrm{C} 1 s$ spectra plotted as a function of laser fluence.

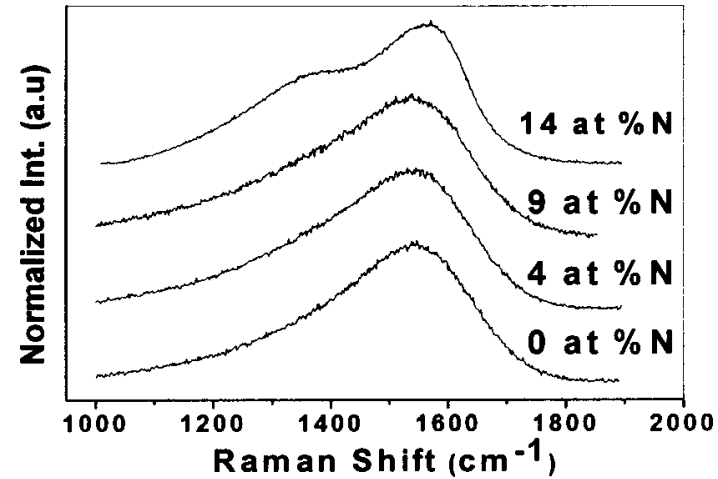

FIG. 5. Raman spectra at 514-nm excitation of films prepared at different nitrogen contents.

bands, respectively. The third approach ${ }^{26,27}$ uses three Gaussian line shapes attributed to $D, G$, and nitrogen $(\mathrm{N})$ bands, respectively. In this report, we will not consider the third approach, as we have not observed a distinct third band in the $D-G$ region. Instead, our analysis will be based on the first and second methods. Recently, Lifshitz ${ }^{48}$ pointed out that a large portion of the Raman data given in the literature is erroneously interpreted. In order to analyze the Raman spectra of $a-\mathrm{CN}_{x}$ films we found that the following questions need to be addressed: (i) What sets of functions should be used to fit the Raman spectra? (ii) Which Raman parameters are most informative and how do the Raman parameters change with excitation laser wavelength? (iii) Is it reliable to estimate $s p^{2}$ cluster size from Raman parameters?

In the following section we will try to give answers to the above questions. The Raman spectra of our films were fitted with two of the more popular methods so that valuable information could be extracted. The first method involved deconvoluting the spectra using two Gaussian functions. ${ }^{33,43-45}$ This allowed us to derive information such as $I_{D} / I_{G}$ ratio, $G$ peak position, and $G$ width. The second method involved fitting the spectra with a $\mathrm{BWF}+L$ line shape ${ }^{46,47,49}$ which is expressed as

$$
I(\omega)=\frac{I_{0}\left[1+2\left(\omega-\omega_{0}\right) / Q \Gamma\right]^{2}}{1+\left[2\left(\omega-\omega_{0}\right) / \Gamma\right]^{2}}+a+b \omega,
$$

where $I(\omega)$ is the Raman-scattered intensity as a function of Raman shift. $I_{0}$ and $\omega_{0}$ are the $G$ peak intensity and $G$ position, respectively, whereas $\Gamma$ is the FWHM, and $a$ and $b$ are constants. The $Q$ parameter is the coupling coefficient or skewness and in the limit of $1 / Q$ approaching 0 , a Lorentzian line shape is recovered. A second Lorentzian line shape was also required for the $D$ peak to improve the quality of the fit. This particular fitting function was utilized as it can be used to provide a binary test (high or low) of the $s p^{3}$ content in the films. ${ }^{46,47,49}$

\section{Effect of nitrogen pressure}

Figure 5 shows the Raman spectra as a function of nitrogen content in the range of $1000-1900 \mathrm{~cm}^{-1}$. The spectra have been normalized to allow for the visualization of changes in the shape and position of the $D$ and $G$ bands upon which patterns or trends can be distinguished. It is clear that as greater amounts of nitrogen are incorporated into the films 


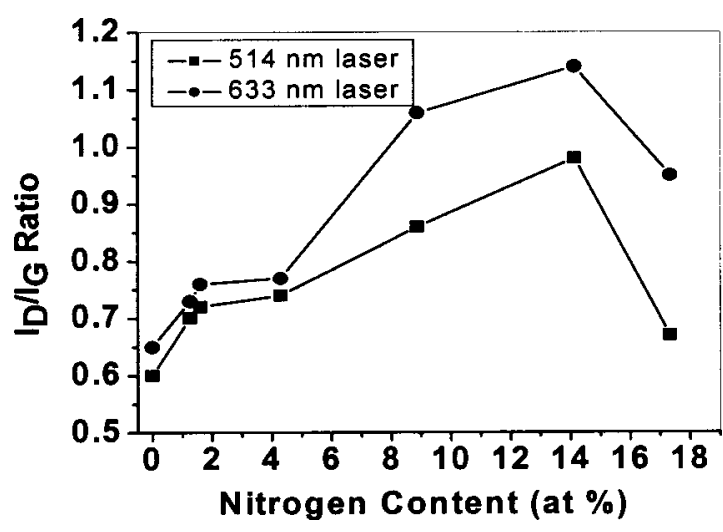

FIG. 6. $I_{D} / I_{G}$ ratios at 514- and $633-\mathrm{nm}$ excitation wavelengths as a function of nitrogen content.

the spectra become more asymmetric. Prominent $D$ peaks can also be observed at 14 at. \% nitrogen concentration suggesting a greater $s p^{2}$ content.

Previous work carried out by Gilkes et al. ${ }^{46}$ implied that a BWF coupling coefficient $(Q)$ lower than -10 is evidence of a $s p^{3}$ fraction of $70 \%$ or more. In all our films the $Q$ factor was greater than -10 , which suggests that our films had a $s p^{3}$ fraction less than $70 \%$. The $I_{D} / I_{G}$ ratio is used to give a qualitative assessment of the induced disorder in the $s p^{2}$ domains and is also related to the clustering of the $s p^{2}$ phase. Figure 6 shows the $I_{D} / I_{G}$ ratio as a function of nitrogen content at two excitation wavelengths. We can see that as the nitrogen content is increased within the films the $I_{D} / I_{G}$ ratio also increases until it reaches a maximum at $14 \%$, after which it falls. This increase in the $I_{D} / I_{G}$ ratio relates to an increase in the number and size of disordered $s p^{2}$ sites according to the relationship,

$$
\frac{I_{D}}{I_{G}}=C(\lambda) L_{a}^{2},
$$

where $C$ is a constant with a value of approximately 0.0055 $\mathrm{nm}$ for $514 \mathrm{~nm}$ and $L_{a}$ is the in-plane crystalline size. The above relationship is valid for crystalline sizes smaller than $20 \AA$ A . From our calculations the cluster size (probed by 514-nm excitation) increased from 10 to $13.35 \AA$ as the nitrogen content increased from $0 \%$ to $14 \%$. However, when the crystallite sizes are greater than $20 \AA$ the $I_{D} / I_{G}$ ratio decreases and the Tuinstra and Koening relationship is effective in which the ratio peak intensity varies inversely with $L_{a}{ }^{42}$

$$
\frac{I_{D}}{I_{G}}=\frac{C(\lambda)}{L_{a}} .
$$

In the case of the films prepared with 17 at. $\% \mathrm{~N}$ a drop in the intensity ratio is observed. This is attributed to the increase in crystalline size in which the relationship described in Eq. (3) takes effect.

The width of the $G$ peak has already been well established as being related to the bond angle disorder at the $s p^{2}$ sites within $a$-C. ${ }^{42}$ Figure 7 shows the $G$ width of the films taken with 514- and 633-nm excitation wavelengths. The narrowing of the peaks as nitrogen incorporation is increased suggests the development of long-range order in the $a$-C.

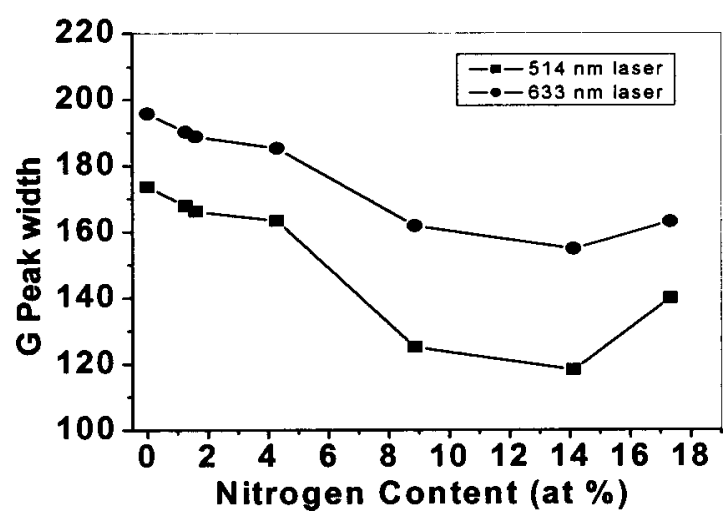

FIG. 7. FWHM of the $G$ peak as a function of nitrogen.

Previous work by Ferrari et al. ${ }^{47}$ reported that the FWHM of the $G$ band decreases continuously as the cluster size increases. Thus the lowering of the $G$ width as a function of nitrogen indicates an increase in the cluster size, which supports our previous calculations. Figure 8 shows the fitted $G$ position as a function of nitrogen content. The graph indicates that a shift to higher wave numbers takes place with greater nitrogen concentrations. The increase in the $G$ position agrees with previous work by Prawer et al. ${ }^{49}$ who reported an increase in the $G$ position, representing an increase in the $s p^{2}$ content.

Recently Ferrari et al. ${ }^{47}$ suggested the $G$ peak dispersion as the most informative parameter for Raman analysis of all $a-\mathrm{CN}_{x}$ films. We found that this is a quite tempting statement and needs to be considered with care due to three simple reasons. First, the $G$ line shape and dispersion of any carbon films depend on various factors such as film thickness, deposition condition, substrate, laser wavelength, and to some extent on instrumental precision. Second, several researchers ${ }^{50,51}$ found that the $G$ peak of the Raman spectrum shifts to higher wave numbers with the increase of compressive stress and a recent report by Shi et al. ${ }^{45}$ found no systematic dispersion of $G$ peak in ta- $\mathrm{CN}_{x}$ films. Third, the data presented here confirm that other Raman parameters such as $I_{D} / I_{G}, G$ width varied significantly with $\mathrm{N}$ at. $\%$ as did the $G$ peak position.

The interpretation of Raman results should be presented carefully. ${ }^{52}$ It is important to note that Raman parameters may vary with a change in the fitting window. Therefore, a

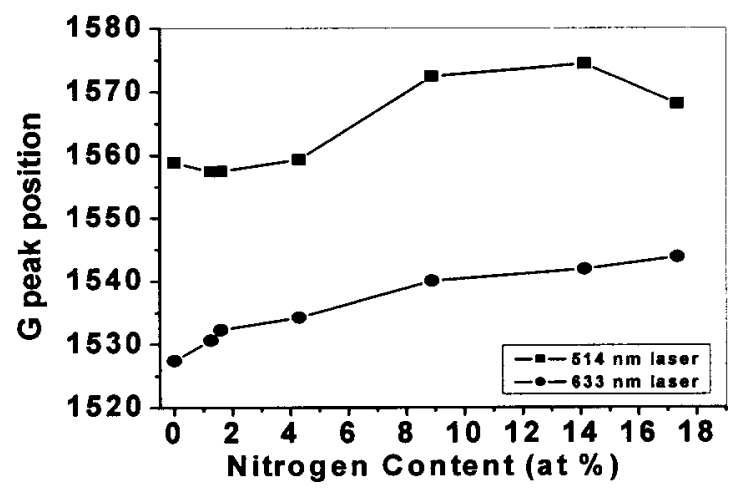

FIG. 8. $G$ peak position as a function of nitrogen content. 


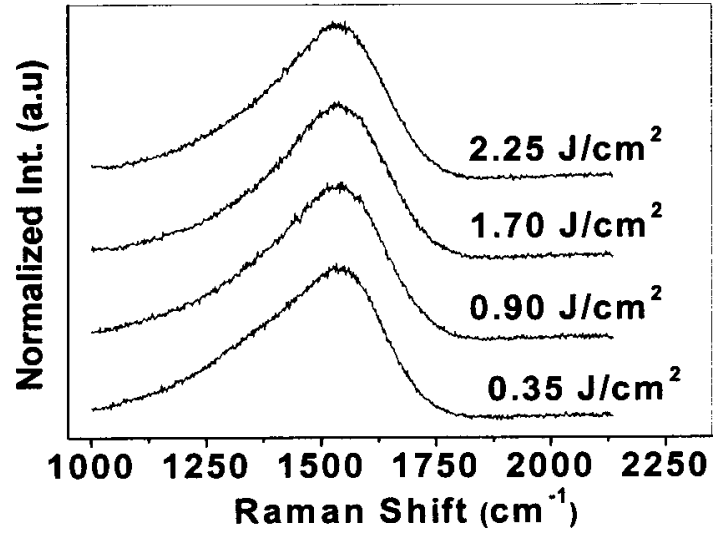

FIG. 9. The Raman spectra of films prepared at various laser fluences.

fixed window should be used for accuracy in results. In our case we fitted the spectra within a window of $1000-1900 \mathrm{~cm}^{-1}$. It should be a priority to mention the fitting window in research papers so that it can be considered when comparing results from the literature. Fitting parameters can also change significantly with the choice of fitting function. The trend of Raman parameters with deposition condition is most important rather than the absolute magnitude of Raman parameters in $a-\mathrm{C}$ and $a-\mathrm{CN}_{x}$ films. Errors in the Raman fitting parameters appear mainly due to base line correction and a suitable background function can minimize the error. We should mention that in our experiments the error in the Raman fitting parameters was negligible and did not have any influence on the trends with deposition conditions such as laser fluence or nitrogen pressure.

\section{Effect of laser fluence}

Figure 9 shows the Raman spectra of the samples prepared at different laser fluences in the range of $1000-1900 \mathrm{~cm}^{-1}$. From the spectra we can see that the $G$ peak becomes more symmetric as laser fluence is increased. This is indicative of an increase in the $s p^{3}$ content of the films. $I_{D} / I_{G}$ ratio and $G$ width were derived by fitting the spectra with two Gaussian line shapes. Figure 10 shows the trend of the intensity ratio as a function of laser fluence taken at 514- and 633-nm excitation wavelengths. We can see that

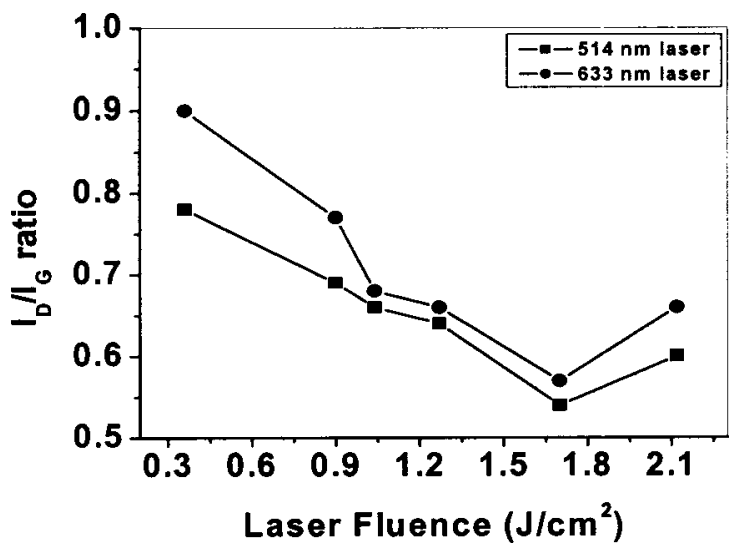

FIG. 10. $I_{D} / I_{G}$ ratio of films prepared at various laser fluences.

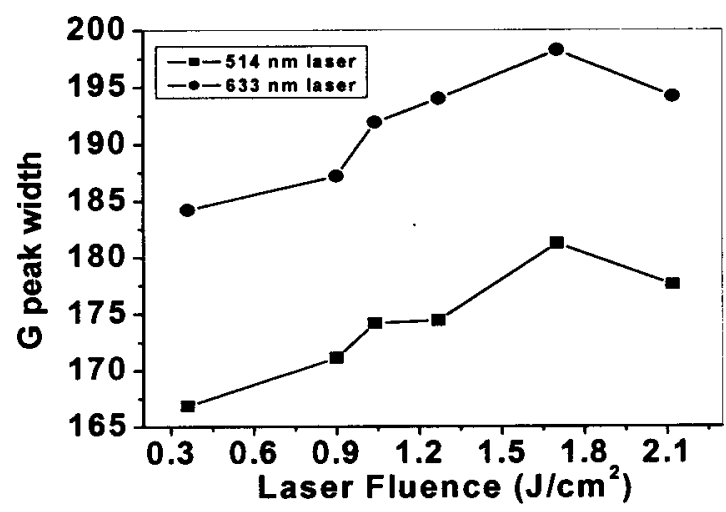

FIG. 11. FWHM of $G$ peak as a function of laser fluence.

a clear trend has developed for both excitations. The fact that the $I_{D} / I_{G}$ ratio continues to fall as laser fluence is increased points to an increase in the $s p^{3} / s p^{3}$ fraction.

Using Eq. (2), we calculated the cluster size of the films prepared at various fluences. We found that the cluster size (probed by 514-nm excitation) decreased from 11.9 to $9.9 \AA$ as the intensity ratio decreased from 0.78 (at $0.36 \mathrm{~J} / \mathrm{cm}^{2}$ ) to 0.54 (at $1.7 \mathrm{~J} / \mathrm{cm}^{2}$ ) indicating an increment of the disorder in the films. Samples prepared at $2.12 \mathrm{~J} / \mathrm{cm}^{2}$ ) revealed an increase in the cluster size to $10.4 \AA$ and a greater degree of order.

The $G$ width has also been plotted as a function of laser fluence (Fig. 11) using two excitation wavelengths. The increase in the FWHM of the $G$ peak as a function of laser fluence is further evidence of an increase in the $s p^{3}$ content of the films. The skewness of these spectra was also analyzed by fitting them with a BWF and a Lorentzian function. The $Q$ factor had decreased from -1.5 to -3.5 as the fluence was increased from 0.36 to $1.7 \mathrm{~J} / \mathrm{cm}^{2}$. At a fluence of $2.12 \mathrm{~J} / \mathrm{cm}^{2}$ the $Q$ parameter was approximately -2.8 suggesting ${ }^{46,49}$ that the $s p^{3}$ content was less than $60 \%$ for all films.

A persistent change in the trend of Raman parameters took place for the films prepared at a fluence of $2.12 \mathrm{~J} / \mathrm{cm}^{2}$. For example, a change in the trend of symmetry ( $Q$ parameter) of the $G$ peak, of the $I_{D} / I_{G}$ ratio, and of the FWHM of the $G$ peak occurred at $2.12 \mathrm{~J} / \mathrm{cm}^{2}$. These changes suggest that there is an optimum laser energy for the growth of films with high $s p^{3}$ bonds. It is expected that the kinetic energy of plasma species will increase with the increase of laser fluence. Although a high kinetic energy ${ }^{42}$ (tens to several hundreds of $\mathrm{eV}$ ) is favorable for the formation of $s p^{3}$ bonding, excessive particle energies ( $\mathrm{KeV}$ regime) are detrimental to the film quality and are responsible for pushing the resultant films into the graphitic regime. ${ }^{2,42}$ We believe that the plasma formed at $2.12 \mathrm{~J} / \mathrm{cm}^{2}$ exhibits two contributions with a fast moving suprathermal ion component preceding a majority of slower thermal ions as identified in previous studies. $^{22}$ These suprathermal ions are responsible for the introduction of $\sigma$ and $\pi$ defects in the films leading to the observed changes in the trends of the Raman parameters.

\section{The effect of two visible wavelengths on the Raman parameters of $\mathrm{CN}_{x}$ and a-C films}

Figures 6 and 10 show the intensity ratios, $I_{D} / I_{G}$, of the films prepared as a function of nitrogen content and laser 
fluence. These were analyzed by both $514-(2.41 \mathrm{eV})$ and $633-\mathrm{nm}(1.95 \mathrm{eV})$ excitation wavelengths for comparative purposes. The two graphs showed similar trends for both wavelengths. However, at $633 \mathrm{~nm}$ the $I_{D} / I_{G}$ ratios were higher for both sets of experiments. This can be explained through the resonant phenomena of Raman scattering. The resonant condition is realized when the excitation energy of the laser is close to the energy of an electronic transition, resulting to an increase in the Raman cross section. By tuning the excitation energy, one can selectively probe the vibrational frequency of different $s p^{2}$ clusters within the $s p^{3}$ matrix. At 633-nm excitation, the $D$ band (breathing modes of $s p^{2}$ atoms in rings only) is more resonant, whereas at 514-nm excitation the $G$ band (bond stretching of all pairs of $s p^{2}$ atoms in both rings and chains) is dominant, which leads to a higher $I_{D} / I_{G}$ ratio for the 633 -nm excitation. In other words, smaller $s p^{2}$ clusters are preferentially excited by higher excitation energy, which in turn lower the $I_{D} / I_{G}$ ratio.

Figures 7 and 11 show the FWHM of the $G$ peak of films prepared as a function of nitrogen and laser fluence, also taken with 514- and 633-nm excitation wavelengths. Again the trends are similar for both wavelengths. The FWHM of the $G$ line when analyzed with $633-\mathrm{nm}$ excitation is much higher than that of $514 \mathrm{~nm}$ and agrees with previous work. ${ }^{50,53}$ Figure 8 shows the variation of the $G$ peak position when analyzed with the two excitation wavelengths. The $G$ peak position is shifted to higher wave numbers at higher excitation energy. This is due to more resonance occurring at the higher photon energy $(2.41 \mathrm{eV})$. This result is in agreement with Wegner et al. ${ }^{54}$ who proposed that smaller clusters possess higher vibrational frequencies than larger ones. From the data presented here one can observe the following relationships between Raman parameters and laser energy in $a-\mathrm{CN}_{x}$ films: (i) the $G$ position and the $-Q$ factor are proportional to the excitation energy; (ii) the $I_{D} / I_{G}$ ratio and the FWHM of the $G$ peak are inversely proportional to the excitation energy.

Although considerable research has taken place on estimating the $s p^{2}$ cluster size by Raman spectroscopy, the accurate size and distribution of $s p^{2}$ cluster in amorphous carbon network are still not well established (in particular, for cluster sizes less than $20 \AA$ ). Some insight can be provided on this aspect from the data presented here. Ferrari and Robertson ${ }^{50}$ have proposed relation (2) for estimating the size of ordered regions from the $I_{D} / I_{G}$ ratio of Raman spectra. It is clear from Eq. (2) that cluster size critically depends on excitation wavelength. Raman mode will disperse with the change of excitation wavelength if the phase contains any $\pi$ bonding. ${ }^{55}$ Since all of our films contain significant amount of $\pi$ bonding we observed dispersion of $G$ peak with wavelength. The $G$ peak dispersion with wavelength (Fig. 8) suggests that smaller clusters exhibit a higher vibrational phonon frequency than larger ones. It appears that our films contain a wide size distribution of carbon clusters and the different cluster sizes have been probed by changing the wavelength. The $I_{D} / I_{G}$ ratio varied significantly with laser energy implying a variable $s p^{2}$ cluster size in our films.

\section{Conclusions from Raman analysis}

The following conclusions can be drawn from our Raman analysis:

(i) A combination of spectroscopic techniques is always desirable to obtain a clear understanding of the structure of $a-\mathrm{CN}_{x}$ films. A set of normalized Raman spectra over at least two wavelengths and the fitting of those by a $\mathrm{BWF}+L$ and two Gaussian functions can be used to gain powerful information about the composition of the films. BWF $+L$ function is less informative for lower $s p^{3}$ content films. However, two Gaussians are useful for both the low and high $s p^{3}$ content films

(ii) The $G$ peak position, $G$ peak width, and $I_{D} / I_{G}$ ratio were found to vary systematically with the laser fluence and nitrogen pressure. It is difficult to point out which is the most informative parameter. It appears that the above parameters along with the skewness of $G$ peak may be taken into account in the analysis of the Raman spectra of $a-\mathrm{CN}_{x}$ films.

(iii) Determination of $s p^{2}$ cluster size from Raman is only indicative, as the cluster size in $a-\mathrm{CN}_{x}$ films is not independent of excitation wavelength. Laser excitation selectively probes clusters with different sizes. More research is needed to elucidate this issue, in particular, for $a$-C films with a very small cluster size $(<20 \AA)$.

\section{Fourier transform infrared (FTIR) analysis}

For basic understanding of the bonding configurations in nitrogenated carbon films, FTIR is considered as a very useful technique. In general, it was observed that the number of "CN" triple bond increases with nitrogen content, ${ }^{56}$ although a similar trend is not clear for $\mathrm{CN}$ single and double bonds. ${ }^{57,58}$ The reason is that the separation of the peaks corresponding to $\mathrm{C}-\mathrm{N}, \mathrm{C}=\mathrm{N}$, and $\mathrm{N}=\mathrm{H}$ bonds in the region of $1100-1750 \mathrm{~cm}^{-1}$ is very difficult and even the presence of nitrogen atoms in $s p^{2}$ carbon clusters breaks the symmetry of the $G$ mode of the Raman spectra to give rise to $D$ and $G$ bands in the IR spectra. ${ }^{57,58}$

The features observed in the present FTIR spectra shown in Fig. 12 are as follows: The region between 700 and $1050 \mathrm{~cm}^{-1}$ indicates the presence of large $s p^{2}$ domains. The region between 1300 and $1700 \mathrm{~cm}^{-1}$ is the representative of broad features of $\mathrm{C}=\mathrm{N}, \mathrm{C}-\mathrm{N}$ stretching and also responsible for $\mathrm{CH}_{2}$ and $\mathrm{CH}_{3}$ vibrations. Moreover the absorption peaks at about 1400 and $1550 \mathrm{~cm}^{-1}$ correspond to $\mathrm{C}-\mathrm{N}$, $>\mathrm{C}=\mathrm{C}<$, and $>\mathrm{C}=\mathrm{N}$-bonds, respectively. The strong absorption between 2900 and $3250 \mathrm{~cm}^{-1}$ corresponds to the vibration of $\mathrm{CH}_{n}(n=1,2,3)$ and even $\mathrm{NH}_{2}$ bonds too (see inset of Fig. 12), whereas the region between 3200 and $3500 \mathrm{~cm}^{-1}$ indicates the presence of mostly $\mathrm{NH}$ bonds ${ }^{59,60}$ and at higher energy $\left(>3500 \mathrm{~cm}^{-1}\right)$ it is contribution of $\mathrm{O}_{2}$, which is due to contamination of the films from the environment. The presence of "NH" bond intensity is used to study the degree of attachment of $\mathrm{H}$ to $\mathrm{C}$ or $\mathrm{N}$ sites. ${ }^{61,62}$ The doublet peaks observed at $\sim 2300 \mathrm{~cm}^{-1}$, attributed as environ- 


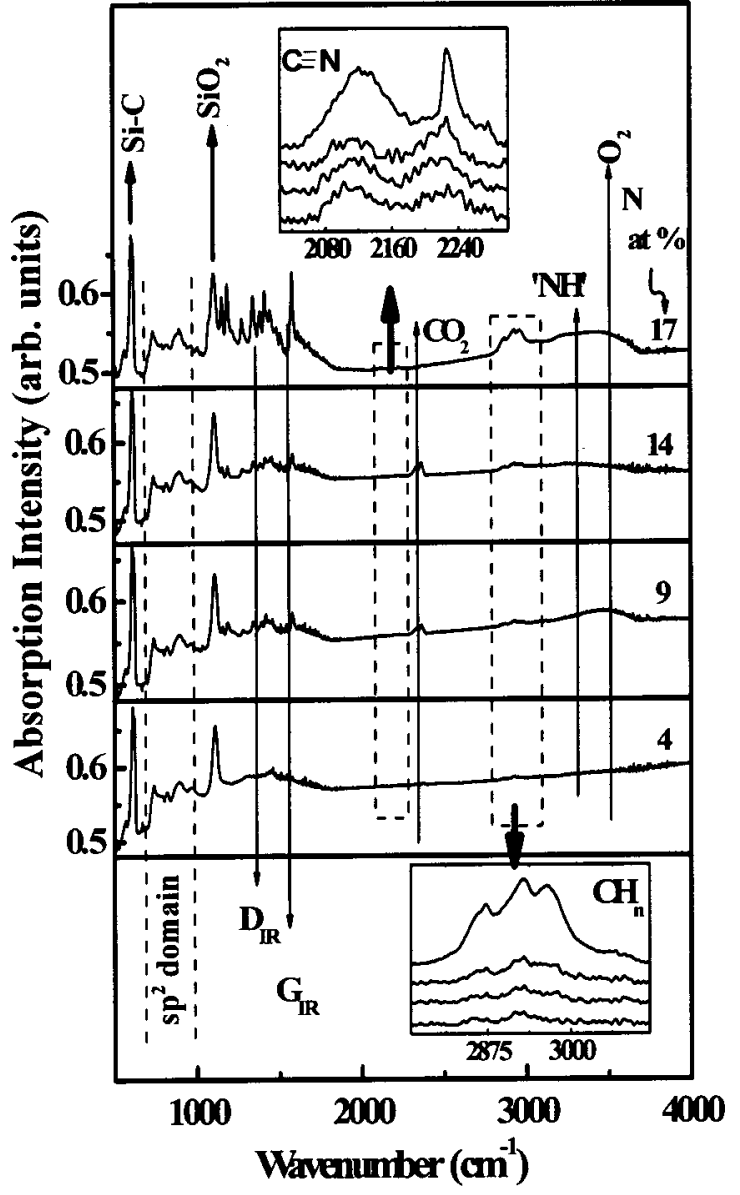

FIG. 12. FTIR absorption spectra of $a-\mathrm{CN}_{x}$ films with different nitrogen concentrations.

mental $\mathrm{CO}_{2}$, and the other two sharp peaks at 612 and $1100 \mathrm{~cm}^{-1}$, which are $\mathrm{Si}-\mathrm{C}$ and $\mathrm{SiO}_{2}$, present in the silicon wafer before deposition.

The most striking features in FTIR spectra from the $a$-CN films are the $D_{\mathrm{IR}}$ and $G_{\mathrm{IR}}$ lines (see Fig. 12) and the peaks $\sim 2100$ and $2200 \mathrm{~cm}^{-1}$ corresponding to $\mathrm{CN}$ triple bonds. The $D_{\mathrm{IR}}$ and $G_{\mathrm{IR}}$ regions indicate an increase in the peak intensity as greater amounts of nitrogen are incorporated into the film. This suggests the formation of $\mathrm{CN}$ double bonds since this IR band is located at the same wave-number range as $\mathrm{C}=\mathrm{N}$ bonds and conjugated $\mathrm{C}=\mathrm{N}$ bonds in rings. This is in agreement with previous work carried out by Zhang et al..$^{32}$ Additionally there was a very small amount of $\mathrm{C}=\mathrm{N}$ nitrile groups observed in which their peak intensities increased with nitrogen concentration as shown in the inset above in Fig. 12. At the highest nitrogen concentration (17 at. \%) in the present films, an intense of the absorbance of peaks at $2225 \mathrm{~cm}^{-1}$ (see inset of Fig. 12) and $\sim 3400 \mathrm{~cm}^{-1}$ is observed which corresponds to the $\mathrm{C} \equiv \mathrm{N}$ nitrile group conjugated to aromatic rings and $\mathrm{N}-\mathrm{H}$ stretching, respectively. The structure of the molecule is close to that of thioamides or amides. Another peak at $2130 \mathrm{~cm}^{-1}$ appeared (see inset of Fig. 12), which indicates that isonitrile element and $s p^{1}$-type carbon structure are present. These results suggest that nitrogen not only breaks the symmetry of aromatic rings but also produces a distorted ring structure in the carbon network.
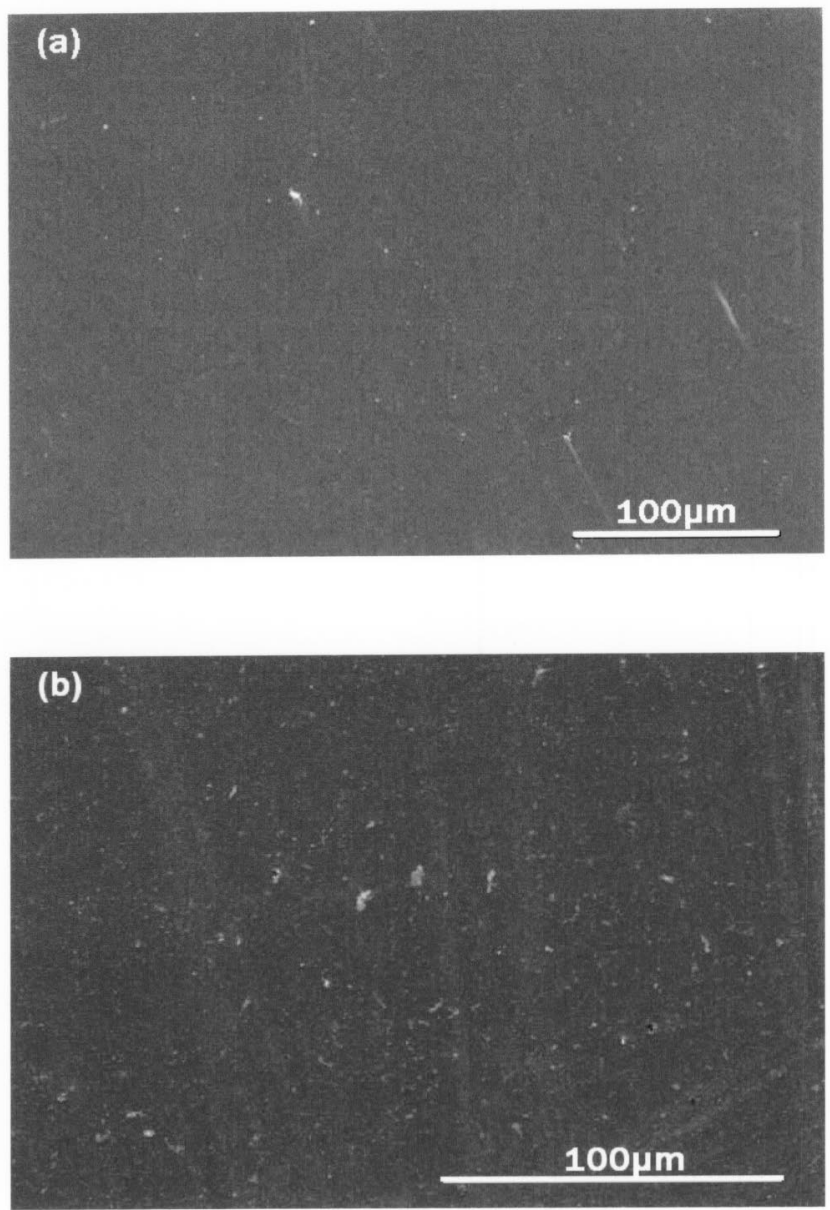

FIG. 13. SEM images of samples prepared at (a) $2.12 \mathrm{~J} / \mathrm{cm}^{2}$ and (b) at $0.9 \mathrm{~J} / \mathrm{cm}^{2}$.

\section{Surface morphology}

A study by Rode et al. ${ }^{19}$ using two Nd:YAG (yttrium aluminum garnet) lasers compared the results of $a$-C samples synthesized with one laser in the nanosecond regime (120 ns) with a high repetition rate of $10 \mathrm{KHz}$ and the other laser in the ultrafast regime (60 ps) combined with a very high repetition rate of $76 \mathrm{MHz}$. Atomic force microscopy (AFM) results ${ }^{20}$ showed that the films produced in the picosecond regime were practically free of submicron irregularities and appeared to be atomically smooth with surface variations of approximately $1 \mathrm{~nm}$.

The scanning electron microscopy (SEM) images in our study of two samples prepared under different laser fluences revealed particulates and are shown in Figs. 13(a) and 13(b). The images reveal that there are a greater number of particles implanted within the sample prepared at $2.12 \mathrm{~J} / \mathrm{cm}^{2}$. The sample prepared at a lower fluence $\left(0.9 \mathrm{~J} / \mathrm{cm}^{2}\right)$ revealed particle size to be smaller and more sparse. Surface morphology results of the $a-\mathrm{CN}_{x}$ also revealed particulates on the surface; however, no clear trend could be distinguished between the particle size or density as a function of nitrogen content.

\section{E. Nanoindentation analysis}

The measurement of the intrinsic nanomechanical properties of thin films is a challenge due to the effect of the 

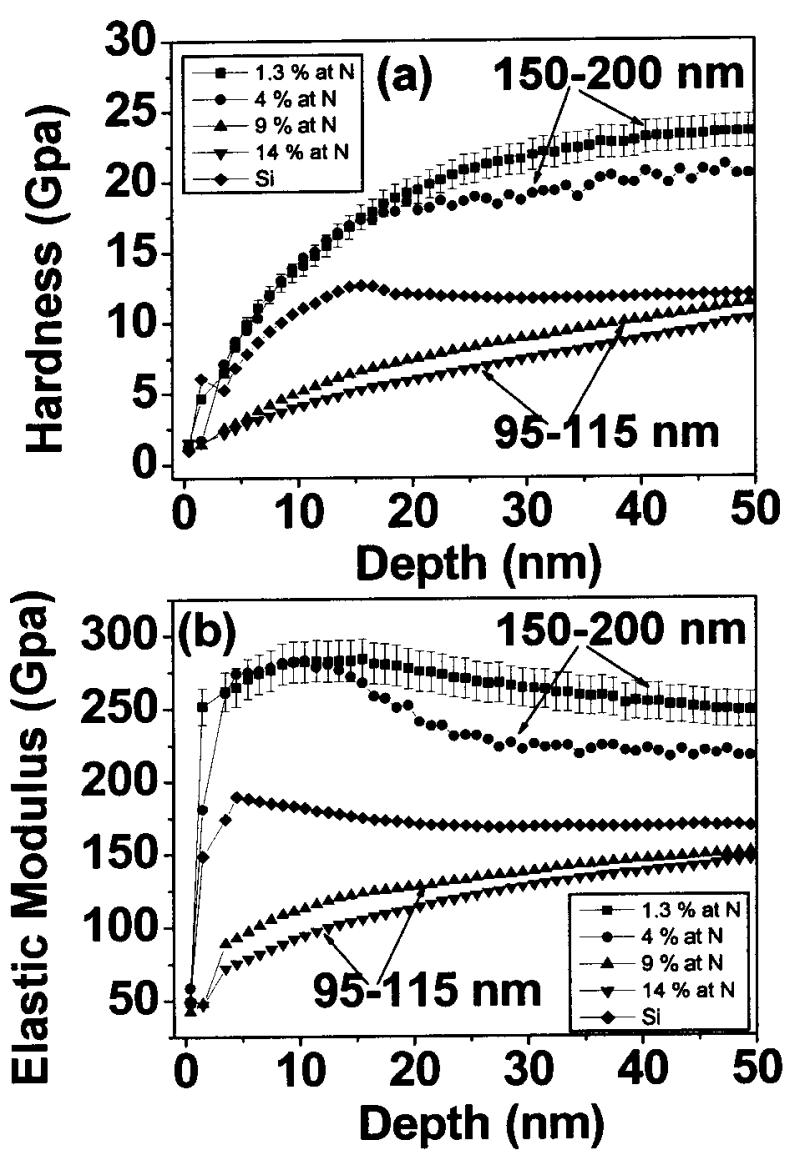

FIG. 14. Hardness and elastic modulus values as a function of indentation depth for $a-\mathrm{CN}_{x}$ films containing various nitrogen contents.

underlying substrate. It is claimed that indentations with contact depths of less than $10 \%$ of the film thickness are needed to obtain intrinsic film properties and void the influence of the substrate. Due to equipment limitations such as machine resolution, signal-to-noise ratio, inaccuracies in tip area calibration, and incomplete subtraction of the Hertzian behavior it is very difficult to obtain meaningful analytical results for indentation depths less than $20 \mathrm{~nm}$. Bearing in mind the above, it is obvious that it is not possible to obtain substrateindependent results for films less than $200 \mathrm{~nm}$ thick (since $10 \%$ of $200 \mathrm{~nm}$ is $20 \mathrm{~nm}$ ). Therefore, in order to analyze films less than $200 \mathrm{~nm}$ thick it is essential to monitor the mechanical properties as a function of depth in order to obtain an insight into the influence of the substrate.

Figures 14(a) and 14(b) represent the hardness and elastic modulus as a function of indentation depth for the $a-\mathrm{CN}_{x}$ films fabricated at various nitrogen pressures. The data points represent the average hardness and elastic modulus values based on nine different load/displacement tests. To illustrate the effect of nitrogen dependence on the nanomechanical properties and rank the films it is essential for all of them to have the same thickness. It is well known that pulsed laser deposition due to the directional nature of the plume produces nonuniform films and as a result the thickness can vary markedly along the substrate. Specific routes have to be employed to alleviate the nonuniformity problem such as rastering of the laser beam, the substrate, or both. ${ }^{63}$ In our case the depositions were carried out by a stationary beam and therefore large nonuniformity problems incurred (30-nm variations on a $10 \times 10$-mm substrate). Moreover, the introduction of nitrogen into the chamber affects the deposition rate. The kinetic energy of the ablated species decreases with nitrogen pressure due to numerous collisions with the background $\mathrm{N}_{2}$ molecules. Since the deposition time was kept constant $(15 \mathrm{~min})$ it was not possible to obtain films with exactly the same thickness. However, for purposes of comparison, we present in Fig. 14 two sets of $a-\mathrm{CN}_{x}$ : (i) films containing $1.3 \%$ and $4 \%$ at $\mathrm{N}$ with thickness in the range of $150-200 \mathrm{~nm}$ and (ii) films containing $9 \%$ and $14 \%$ at $\mathrm{N}$ approximately 95-115 $\mathrm{nm}$ thick.

In the first set of hardness curves (films containing 1.3\% and $4 \%$ at N) two stages can be clearly resolved. First, the hardness increases sharply as the indentation increases up to $20 \mathrm{~nm}$. Second, for indentation depths of higher than $20 \mathrm{~nm}$ hardness remains stable or increases at a much smaller rate. The $E(d)$ curves show also two stages. A rapid increase up to $10 \mathrm{~nm}$ followed by a decrease approaching values closer to the substrate $(\sim 170 \mathrm{GPa})$. The $a-\mathrm{CN}_{x}$ film containing $1.3 \%$ and $4 \%$ at $\mathrm{N}$ has hardness values of $\sim 23$ and $\sim 19 \mathrm{GPa}$, respectively, at an indentation depth of $30 \mathrm{~nm}$ ( $\sim 15 \%$ of film thickness). Due to inaccuracy in film thickness $(30 \mathrm{~nm})$ it is not possible to ascertain if this small reduction is due to a lower thickness or incorporation of nitrogen.

In the second set of hardness curves (films containing $9 \%$ and $14 \%$ at $\mathrm{N}$ ) both hardness and elastic modulus values rise to approach the corresponding values of the substrate ( $\sim 11.8$ and $\sim 170 \mathrm{GPa}$, respectively). This increasing slope demonstrates a pronounced softening effect, which is mainly attributed to the nitrogen incorporation. These films are softer than the Si substrate and as indentation depth is increasing the effect of the substrate becomes more apparent. The $a-\mathrm{CN}_{x}$ film containing $9 \%$ and $14 \%$ at $\mathrm{N}$ has hardness values of $\sim 8$ and $\sim 6 \mathrm{GPa}$, respectively, at an indentation depth of $20 \mathrm{~nm}$ ( $\sim 20 \%$ of film thickness). The reduction in hardness and elasticity is a result of the nitrogen being incorporated into the film network. The results show that the incorporation of nitrogen at high nitrogen levels reverts the $s p^{3}$ network to $s p^{2}$, exhibiting the soft characteristics of graphite.

\section{SUMMARY}

In this study $a-\mathrm{CN}_{x}$ and $a-\mathrm{C}$ with a nitrogen content up to 17 at. \% were grown on HF-etched $p$-type silicon by ultrafast high repetition rate PLD as a function of nitrogen partial pressure and laser fluence, respectively. The C $1 s$ XPS showed that the $\mathrm{CN}$ fraction increased at the expense of $\mathrm{CC}$ bonds with an increase of $\mathrm{N}$ content in the films. Films prepared as a function of laser fluence revealed a distinct trend in that as laser fluence increased so did the $s p^{3}$ content.

Raman analysis agreed with XPS results in that the size or number of $s p^{2}$ sites in the samples increased as a function of nitrogen partial pressure. These results were compounded as $I_{D} / I_{G}$ ratio and $G$ peak position increased while the FWHM of the $G$ peak decreased. The decrease in the $I_{D} / I_{G}$ ratio as well as an increase in the FWHM of the $G$ peak indicated that $s p^{2}$ sites decreased as a function of laser flu- 
ence. The results also showed that there was an optimum laser fluence for the growth of $s p^{3}$ bonds and when exceeded formation of $s p^{3}$ bonds no longer took place (laser fluence of $\left.2.12 \mathrm{~J} / \mathrm{cm}^{2}\right)$.

FTIR analysis indicated an increase in the $\mathrm{CN}$ double bonds as more nitrogen was added to the films. Also observed in very small amounts were $\mathrm{C} \equiv \mathrm{N}$ bonds. Surface morphology analysis also revealed that samples contained particulates particularly in the case of the samples prepared as a function of laser fluence in which a greater particle density occurred at higher laser fluences. Hardness and elasticity measurements from nanoindentation analysis were in agreement with our XPS and Raman analysis.

\section{ACKNOWLEDGMENTS}

This work was supported by the European Union through the "Access to research infrastructures programme," at the Institute of Electronic Structure and Laser Applications in Crete.

${ }^{1}$ A. Grill, Diamond Relat. Mater. 8, 428 (1999).

${ }^{2}$ A. Y. Liu and M. Cohen, Science 24, 841 (1989).

${ }^{3}$ A. K. Sharma and J. Narayan, Int. Mater. Rev. 42, 137 (1997).

${ }^{4}$ H. Xin, W. Xu, X. Shi, H. Zhu, C. Lin, and S. Zou, Appl. Phys. Lett. 66 , 3290 (1995).

${ }^{5}$ S. P. Withrow, J. M. Williams, S. Prawer, and D. Barbara, J. Appl. Phys. 78, 3060 (1994).

${ }^{6}$ C. W. Ong, X. A. Zhao, Y. C. Tsang, C. L. Choy, and P. W. Chan, Thin Solid Films 280, 1 (1996).

${ }^{7}$ A. Zocco, A. Perrone, E. D'Anna, G. Leagieri, A. Luches, A. Klini, I. Zergioti, and C. Fotakis, Diamond Relat. Mater. 8, 582 (1999).

${ }^{8}$ A. Bousetta, M. Lu, and A. Bensaoula, J. Vac. Sci. Technol. A 13, 1939 (1995).

${ }^{9}$ M. Diani, A. Mansour, L. Kubler, J. L. Bischoff, and D. Bolmot, Diamond Relat. Mater. 13, 1939 (1994).

${ }^{10}$ X. Wang, and P. J. Martin, Appl. Phys. Lett. 68, 1177 (1996).

${ }^{11}$ S. Kumar, and T. L. Tansley, J. Appl. Phys. 76, 4390 (1994).

${ }^{12}$ K. M. Yu, M. L. Cohen, E. E. Haller, W. L. Hansen, A. Y. Liu, and I. C. Wu, Phys. Rev. B 49, 5034 (1994).

${ }^{13}$ N. Hellgren, M. P. Johansson, E. Broitman, L. Hultman, and J. E. Sundgren, Phys. Rev. B 59, 5162 (1999).

${ }^{14}$ L. K. Cheah, X. Shi, J. R. Shi, E. J. Liu, and S. R. P. Silva, J. Non-Cryst. Solids 242, 40 (1998).

${ }^{15}$ A. Zocco, A. Perrone, E. Broitman, Zs. Czigany, L. Hultman, M. Anderle, and N. Laidani, Diamond Relat. Mater. 11, 98 (2002).

${ }^{16}$ K. J. Koivusaari, J. Levoska, and S. Leppavuori, J. Appl. Phys. 85, 2915 (1999).

${ }^{17}$ Z. Y. Chen, J. P. Zhao, T. Yano, and T. Ooie, J. Appl. Phys. 92, 281 (2002).

${ }^{18}$ P. Papakonstantinou, N. A. Vainos, and C. Fotakis, Appl. Surf. Sci. 151, 159 (1999).

${ }^{19}$ A. V. Rode, B. Luther-Davies, and E. G. Gamaly, J. Appl. Phys. 85, 4222 (1999).

${ }^{20}$ A. S. Loir et al., Appl. Surf. Sci. 208-209, 553 (2003).

${ }^{21}$ Z. Geretovszky, Z. Kántor, I. Bertóti, and T. Szőrényi, Appl. Phys. A: Mater. Sci. Process. 70, 9 (2000).

${ }^{22}$ F. Qian, V. Craciun, R. K. Singh, S. D. Dutta, and P. P. Pronko, J. Appl. Phys. 86, 2281 (1999).

${ }^{23}$ Zs. Geretovszky, Z. Kántor, and T. Szőrényi, Appl. Surf. Sci. 208-209, 547 (2003).

${ }^{24}$ A. Ilie, C. Durkan, W. I. Milne, and M. E. Welland, Phys. Rev. B 66, 045412 (2002).

${ }^{25}$ E. Riedo, F. Comin, J. Chevrier, and A. M. Bonnot, J. Appl. Phys. 88, 4365 (2000).
${ }^{26}$ D. Das, K. H. Chen, S. Chattopadhyay, and L. C. Chen, J. Appl. Phys. 91, 4944 (2002).

${ }^{27}$ S. Bhattacharyya, C. Vallee, C. Cardinaud, and G. Turban, J. Appl. Phys. 87, 7524 (2000).

${ }^{28}$ S. Bhattacharyya, C. Cardinaud, and G. Turban, J. Appl. Phys. 83, 4491 (1998).

${ }^{29}$ Z. Y. Chen, J. P. Zhao, T. Yano, and T. Ooie, J. Appl. Phys. 92, 281 (2002).

${ }^{30}$ S. S. Roy, P. Papakonstantinou, R. McCann, G. Abbas, J. P. Quinn, and J. A. McLaughlin, Diamond Relat. Mater. 13, 1459 (2004).

${ }^{31}$ M. Yoshikawa, K. Iwagami, T. Matsunobe, N. Morita, Y. Yamaguchi, and Y. Izumi, Phys. Rev. B 69, 045410(R) (2004).

${ }^{32}$ X. W. Zhang, N. Ke, W. Y. Cheung, and S. P. Wong, Diamond Relat. Mater. 12, 1 (2003).

${ }^{33}$ P. Papakonstantinou and P. Lemoine, J. Phys.: Condens. Matter 13, 2971 (2001).

${ }^{34}$ W. C. Oliver, and G. M. Phar, J. Mater. Res. 7, 1564 (1992).

${ }^{35}$ C. Ronning, H. Feldermann, R. Merk, H. Hofsäss, P. Reinke, and J.-U. Thiele, Phys. Rev. B 58, 2207 (1998).

${ }^{36}$ D. Das, K. H. Chen, S. Chattopadhyay, and L. C. Chen, J. Appl. Phys. 91, 4944 (2002)

${ }^{37}$ T. W. Scarf, R. D. Ott, D. Yang, and J. A. Barnard, J. Appl. Phys. 85, 3142 (1999).

${ }^{38}$ H. Sjostrom, L. Hultman, J. E. Sundgren, S. V. Hainsworth, T. F. Page, and S. S. A. M. Theunissen, J. Vac. Sci. Technol. A 14, 56 (1996).

${ }^{39}$ W. T. Zheng, Y. Sakamoto, J. H. Guo, X. T. Li, P. J. Cao, Z. S. Jin, and M. Takaya, Phys. Rev. B 64, 016201 (2001).

${ }^{40}$ J. M. Ripalda et al., Phys. Rev. B 64, 016201 (2001).

${ }^{41}$ A. Snis and S. F. Matar, Phys. Rev. B 60, 10855 (1999).

${ }^{42}$ J. Robertson, Mater. Sci. Eng., R. 37, 129 (2002).

${ }^{43}$ P. Merel, M. Tabbal, M. Chaker, S. Moisa, and J. Margot, Appl. Surf. Sci. 136, 105 (1998).

${ }^{44}$ N. Hellgren, J. Guo, C. Sathe, A. Agui, J. Nordgren, Y. Luo, H. Àgren, and J. Sundgren, Appl. Phys. Lett. 79, 4348 (2001).

${ }^{45}$ J. R. Shi, J. P. Wang, A. T. S. Wee, C. B. Yeo, C. T. Cheng, M. Ueda, S. Tomioka, and J. Ohsako, J. Appl. Phys. 92, 5966 (2002).

${ }^{46}$ K. W. R. Gilkes, S. Prawer, K. W. Nugent, J. Robertson, H. S. Sands, Y. Lifshitz, and X. Shi, J. Appl. Phys. 87, 7283 (2000).

${ }^{47}$ A. C. Ferrari, S. E. Rodil, and J. Robertson, Phys. Rev. B 67, 155306 (2003).

${ }^{48}$ Y. Lifshitz, Diamond Relat. Mater. 12, 130 (2003).

${ }^{49}$ S. Prawer, K. W. Nugent, Y. Lifshitz, G. D. Lempert, E. Grossman, J. Kulik, and I. Avigal, Diamond Relat. Mater. 5, 433 (1996).

${ }^{50}$ A. C. Ferrari and J. Robertson, Phys. Rev. B 64, 075414 (2001).

${ }^{51}$ J.-K. Shin, C. S. Lee, K.-R. Lee, and K. Y. Eun, Appl. Phys. Lett. 78, 631 (2001).

${ }^{52}$ J. Schwan, S. Ulrich, V. Bathori, H. Erhardt, and S. R. P. Silva, J. Appl. Phys. 80, 440 (1996).

${ }^{53}$ A. C. Ferrari, S. E. Rodil, and J. Robertson, Diamond Relat. Mater. 12, 905 (2003)

${ }^{54}$ J. Wegner, M. Ramsteiner, Ch. Wild, and P. Koidl, Phys. Rev. B 40, 1817 (1989).

${ }^{55}$ J. Robertson, Diamond Relat. Mater. 13, 1558 (2004).

${ }^{56}$ K. Ogata, J. F. D. Chubaci, and F. Fujimato, J. Appl. Phys. 76, 3791 (1994).

${ }^{57}$ S. R. P. Silva, J. Robertson, G. A. J. Amaratunga, B. Rafferty, L. M. Brown, J. Schwan, D. F. Franceschini, and G. M. Mariotto, J. Appl. Phys. 81, 2626 (1997).

${ }^{58}$ D. R. Mckenzie, D. A. Muller, and B. A. Pailthorpe, Phys. Rev. Lett. 67, 773 (1991)

${ }^{59}$ N. V. Novikov, M. A. Voronkin, A. A. Smekhnov, N. I. Zaika, and A. P. Zakharchuk, Diamond Relat. Mater. 4, 3905 (1995).

${ }^{60}$ F. Demichelis, X. F. Rong, S. Schreiter, A. Tagliaferro, and C. DeMartino, Diamond Relat. Mater. 4, 361 (1995).

${ }^{61}$ J. Shiao and W. Hoffman, Thin Solid Films 283, 145 (1996).

${ }^{62}$ P. Hammer, N. M. Victoria, and F. Alvarez, J. Vac. Sci. Technol. A 16, 2941 (1998).

${ }^{63}$ P. Papakonstantinou, Ph.D thesis, Queen's University of Belfast, 1994. 